\title{
Las Cooperativas No Agropecuarias en Cuba: su trascendencia socioeconómica y jurídica
}

\author{
Yulier Campos Pérez¹, Lienny García Pedraza², \\ Annia Martínez Massip ${ }^{3}$ \\ Universidad Central de las Villas, Cuba
}

Sumario: I. Introducción. II. La cooperativa no agropecuaria en Cuba: su definición, fines, principios y datos generales. III. Huellas y desafíos socioeconómicos de las CNoA. IV. Trascendencia jurídica de la constitución de cooperativas no agropecuarias en Cuba. V. Conclusiones.

Resumen: El presente artículo se centra en el análisis de la trascendencia socio-económica y jurídica de las cooperativas no agropecuarias en Cuba. En el comienzo se examinan su definición, principios, así como los fines que debe cumplir. La investigación se centra en demostrar las huellas y desafíos socioeconómicos de la CNoA a 7 años de aprobado su marco jurídico. Dichas huellas impactan en el entorno individual, colectivo y social que rodea a la cooperativa. También se analizan los principales retos y oportunidades que estas producen sobre el ordenamiento jurídico cubano y los operadores del Derecho. Por último, se verifica el actual régimen jurídico cooperativo y sus principales desafíos.

Palabras clave: cooperativas no agropecuarias, fines, trascendencia socioeconómica, importancia jurídica.

Abstract: The present article focus its attention on the analysis of the socio- economic and legal transcendence of the non-agrarian cooperatives in Cuba. At the beginning its definition, principles as well as the aims to be achieved are examined. It's very important to highlight how the phenomenon can be seeing from the practical point of view, it's shown through the understanding of the general data. Nowadays the research is focus on the demon-

1 MSc. Yulier Campos Pérez, Profesor Auxiliar Departamento de Derecho, Universidad Central «Marta Abreu» de Las Villas. Correo electrónico: ycperez@uclv.edu.cu

2 Lic. Lienny García Pedraza, Profesora Asistente, Departamento de Sociología, Universidad Central «Marta Abreu» de Las Villas. Correo electrónico: liennygp@uclv.cu

3 Dr. C. Annia Martínez Massip, Profesora Titular, Departamento de Sociología, Universidad Central «Marta Abreu» de Las Villas. Correo electrónico: massip@uclv.edu.cu 
stration of the socio- economic tracks and challenges of the CNoA since the law was approved. These tracks have an impact on the individual, collective and social environment that surrounds the cooperative. The principal challenges and opportunities that they produce on the new legal and cooperative regime and its main challenges.

Keywords: non- agrarian cooperatives, aims, socio- economic transcendence, legal importance. 


\section{Introducción}

«Desde hace algún tiempo, Cuba ha estado inmersa en uno de los más intensos debates económicos de la historia más reciente del país. De hecho, este se enmarca en una discusión más amplia acerca de la manera en que deben ser enfrentados los desafíos que se le imponen hoy a la Revolución Cubana». ${ }^{4}$ Desafíos en todos los ámbitos, pues no habrá un cambio económico que no trascienda en el sistema social e incluso jurídico del país.

Las cooperativas y la extensión de sus potencialidades en Cuba, han sido uno de estos desafíos que desde la necesidad de producir bienes y prestar servicios hoy inexistentes o maltrechos se han convertido en fuentes de empleo y verdaderos actores sociales y jurídicos.

En el VII Congreso del Partido Comunista de Cuba en 2016, se reafirma la idea del cooperativismo en su sentido amplio, sobre todo en el sector no agropecuario ${ }^{5}$. Sin embargo, la propuesta de estrategia de desarrollo enfoca el cooperativismo en general, en sus dos variantes, agrarias y urbanas. Esta se refleja en la posibilidad de la creación de cooperativas en diferentes sectores y actividades.

4 CARRANZA, J.; MONREAL, P.; GUTIÉRREZ, L.: «Cuba: reestructuración económica, socialismo y mercado». Revista Temas, No.1, pp. 27 y ss.

5 Desde el VI Congreso del Partido Comunista de Cuba celebrado en 2011 los Lineamientos de la Política Económica y Social del Partido y la Revolución aprobados el 18 de abril de ese año, se incluye una clara mención a la constitución de cooperativas como una de las formas de gestión no estatal. De dichos lineamientos se desprenden, entre otras, las siguientes referencias a estas:

— el «modelo reconocerá y promoverá... las cooperativas...» (Numeral 2);

- «Se crearán las cooperativas de primer grado como una forma socialista de propiedad colectiva, en diferentes sectores, las que constituyen una organización económica con personalidad jurídica y patrimonio propio, integradas por personas que se asocian aportando bienes o trabajo, con la finalidad de producir y prestar servicios útiles a la sociedad y asumen todos sus gastos con sus ingresos» (numeral 25);

— «Se crearán cooperativas de segundo grado, cuyos socios son cooperativas de primer grado, las que tendrán personalidad jurídica y patrimonio propio y se forman con el objetivo de organizar actividades complementarias afines o que agreguen valor a los productos y servicios de sus socios (de producción, servicios y comercialización), o realizar compras y ventas conjuntas con vistas a lograr mayor eficiencia.» (Numeral 29);

— «Estudiar la aplicación de estímulos fiscales que promuevan el desarrollo ordenado de las formas de gestión no estatal.» (Numeral 59);

- «Lograr la autonomía de gestión de las distintas formas de cooperativas e introducir de forma gradual las cooperativas de servicios en la actividad agroindustrial a escala local.» (Numeral 180); 
En el lineamiento 161, se reconoce a las cooperativas como «una forma de propiedad colectiva en la que sus trabajadores permanentes son socios con iguales derechos, que participan de la distribución de utilidades de acuerdo con el trabajo aportado. ${ }^{6}$ No obstante, desde 2016 prácticamente no se evidencia incremento en el número de cooperativas no agropecuarias del país, los aumentos se han concentrado en la región occidental. Esto ha provocado desmotivación entre los aspirantes a socios cooperativos del resto del territorio, que ven en ello una contradicción pues la práctica difiere de la voluntad política reconocida.

En este marco el «viejo» y el «nuevo» cooperativismo cubano debe repensarse como movimiento. Su ampliación a otros sectores es un paso de avance. Lo anterior se evidencia en la naturaleza de las nuevas cooperativas (1er grado), la cual ha sido heterogénea, proceden de personas naturales (trabajadores por cuenta propia, productores individuales) o personas jurídicas (empresa estatal), pero de manera general expresan las intenciones del país de ampliar el cooperativismo más allá del sector agropecuario.

"Los estudios sobre el cooperativismo no agropecuario en Cuba son de carácter, esencialmente, exploratorio producto a su reciente conformación. Han analizado el proceso de implementación y formación de las cooperativas refiriéndose a indicadores como: la motivación a partir de la nueva forma de organización del trabajo y la distribución de los ingresos y el ambiente laboral» ${ }^{7}$. De tal manera se resalta la necesidad de estudiar el proceso de creación y formación, la democratización en la toma de decisiones producto a la ausencia de «un sistema de gestión, basado en la experiencia acumulada por las cooperativas agrícolas (...) y de un modelo de organización de las cooperativas asentado en sistemas participativos, democráticos y flexibles que faciliten los procesos de cooperación (...) $\rangle^{8}$ así como su contribución a las localidades cubanas.

El presente trabajo busca identificar la trascendencia de las cooperativas no agropecuarias en Cuba a 7 años de la aprobación del marco

6 PARTIDO COMUNISTA DE CUBA (PCC): Lineamientos de la Política Económica y Social del Partido y la Revolución para el período 2016-2021, No. 161.

7 PINEEIRO HARNECKER, C.: «Nuevas cooperativas cubanas: logros y dificultades», 2015. Disponible en: https://www.researchgate.net/publication/284177761_Nuevas_ cooperativas_cubanas_logros_y_dificultades_marzo_2015

8 DONÉSTEVEZ SÁNCHEZ, G. M., GARCÍA RUIZ, J., FAJARDO NÁPOLES, L., FIGUERAS MATOS, D., MUÑOZ ALFONSO, Y., y MARTINERA HERNÁNDEZ, J. F.: «El nuevo cooperativismo en la Cuba del siglo XXI», En: Muñoz González, R., Donéstevez Sánchez, G. M., García Ruiz, J. (comp.), Desarrollo y cooperativismo. Desafíos al modelo cubano de transición al socialismo (pp. 141-162), Editorial Caminos, La Habana, 2014, p. 10. 
jurídico que permite su constitución. Dicha trascendencia se traduce en los ámbitos social, económico y jurídico.

\section{La cooperativa no agropecuaria en Cuba: su definición, fines, principios y datos generales}

La existencia del cooperativismo en Cuba está unida fundamentalmente al propio desarrollo de la Revolución, por lo menos en lo que a cooperativismo agrario respecta. La extensión del fenómeno hacia sectores distintos del agropecuario es sumamente reciente pues no es hasta el 2011 con la celebración del VI Congreso el Partido Comunista de Cuba (PCC) y la aprobación de Lineamientos de la política económica y social del Partido y la Revolución que se reconoce oficialmente el interés de extender el cooperativismo más allá del sector agrario. En este marco político se hace notar la necesidad de aprobar una norma jurídica que permita la constitución de las mismas en tales sectores.

Cinco años después en el VII Congreso del PCC (2016) se ratifica la importancia y validez en nuestro contexto de tales organizaciones, así como de la consolidación del experimento de las normas a cuatro años de aprobación del Decreto Ley 305 «De las cooperativas no agropecuarias» de 15 de noviembre de 2012 y sus normas complementarias.

Es así que la propia consolidación del experimento provocó que en este 2019 se modificara totalmente el régimen jurídico cubano en materia de cooperativas no agrarias en pos de la actualización de tales disposiciones.

Dicho proceso - experimental en su concepción y diseño- no ha estado exento, como es de suponer, de contratiempos, correcciones, aciertos y desaciertos. Tales tendencias se evidencian desde lo práctico, lo legal, lo teórico, lo económico, etc. No obstante, el saldo del cooperativismo no agropecuario en sentido general es positivo, lo que se demostrará en el presente trabajo.

Según la Alianza Cooperativa Internacional $(\mathrm{ACl})$ la cooperativa es una asociación autónoma de personas que se han unido voluntariamente para hacer frente a sus necesidades y aspiraciones económicas, sociales y culturales comunes por medio de una empresa de propiedad conjunta y democráticamente controlada. ${ }^{9}$

Lo que marca la diferencia, esencialmente, en una cooperativa es la administración democrática desde la colectividad, pues, aunque des-

9 ALIANZA COOPERATIVA INTERNACIONAL PARA LAS AMÉRICAS.: «Definición de Cooperativa», 1995. Disponible en Word Wide Web: http://www.aciamericas.coop/ Definicion-de-Cooperativa. Consultado (10/1/2017). 
pliegan actividades empresariales comunes, la democracia rige la forma de desarrollarlas, la manera en que se reparten los resultados del trabajo, y la forma en que se toman las decisiones más importantes. Según RodRíGuez Musa, "las cooperativas son, primero que todo, entidades integradas por grupos de personas con un objetivo común, que será cumplimentado sobre la base del esfuerzo propio y la ayuda mutua, dando lugar a un espacio asociativo particularmente propicio para potenciar una ética propia». ${ }^{10}$

La Constitución de la República de Cuba, aprobada el 24 de febrero de 2019 y promulgada el 10 de abril del propio año delimita como una forma de propiedad en el Articulo 22 b) a la cooperativa, la misma se sustenta en el trabajo colectivo de sus socios propietarios y en el ejercicio efectivo de los principios del cooperativismo. ${ }^{11} \mathrm{De}$ acuerdo a HERNÁNDEZ AgUILAR y RODRÍGUeZ MusA ${ }^{12}$ " la dañina tradición de explicar a la cooperativa estrictamente como una forma de propiedad nos devuelve a la cuestión medular de su naturaleza jurídica especial». No obstante, a pesar de que el cooperativismo no sea una mera forma de propiedad, sino una forma asociativa especial, el logro de la Constitución es no restringir a las cooperativas a determinados sectores, sino considerarla como un ente genérico y viable en cualquier espacio económico y social cubano.

El novísimo Decreto Ley 366 del 2018 «De las cooperativas no agropecuarias no agropecuarias» ${ }^{13}$ en Cuba, define a una cooperativa como una organización con fines económicos y sociales, que se constituye voluntariamente sobre la base del aporte de bienes y derechos y se sustenta en el trabajo de sus socios.

El mismo continúa la sistemática de la norma predecesora, el Decreto Ley 305 del 2012 pues reconoce a la cooperativa como una mera organización sin delimitar su específica naturaleza jurídica, tema álgido y complejo dentro del Derecho. No obstante, nos parece oportuno

10 RODRÍGUEZ MUSA, O.: «Presupuestos teóricos para el redimensionamiento constitucional de la cooperativa en Cuba». Tesis presentada en opción al grado científico de Doctor en Ciencias Jurídicas. La Habana, 2016. p. 26.

11 Cfr. Constitución de la República de Cuba, 2019 Art 22 b). Gaceta Oficial No. 5 Extraordinaria de 10 de abril de 2019.

12 HERNÁNDEZ AGUILAR, O Y RODRÍGUEZ MUSA, O.: «La cooperativa en el ordenamiento jurídico cubano. Una aproximación crítica a la luz del actual proceso de perfeccionamiento del modelo económico en el país». Boletín de la Asociación Internacional de Derecho Cooperativo, Núm. 45/2011, Bilbao, 2011. pp. 251-269.

13 Decreto Ley 366 «De las cooperativas no agropecuarias no agropecuarias» de fecha 19 de noviembre de 2018 y publicado en la Gaceta Oficial de la República de Cuba a 30 de agosto de 2019 . 
apuntar que sería pertinente que la reconociera como una persona jurídica especial con características propias y consecuentemente con fines también especiales. "Las especificidades de la forma socioeconómica cooperativa, permiten diferenciarla de otras formas de organización para la obtención de los bienes y servicios que requerimos para satisfacer nuestras necesidades». ${ }^{14}$

No aparece en esta definición el carácter democrático de las mismas, cuestión esta que como se dijo antes resulta vital para caracterizarlas e individualizarlas frente a entidades capitalistas por solo citar un ejemplo.

La propia norma reconoce que la misma debe cumplir determinados fines económicos y sociales. Los primeros mucho más claros y específicos a lo interno y externo de la organización. En el caso de los segundos no tan despejados, pues más allá de responder a intereses personales y colectivos, los intereses sociales no se manifiestan de igual manera en todas las cooperativas. Los mismos serán analizados posteriormente.

El propio artículo 2 en el numeral segundo destaca que: "el objetivo general de la cooperativa es la producción de bienes y la prestación de servicios mediante la gestión colectiva para la satisfacción del interés social y el de los socios; constituye una alternativa para relevar al Estado de la administración de aquellas actividades económicas, productivas o de servicios que no se consideren principales». ${ }^{15}$

En este punto los objetivos sociales ocupan el lugar primero en la gestión cooperativa, y es que así debe ser, aunque en la práctica, mayoritariamente no se reconoce de esta manera pues la cotidianeidad solo apunta a la retribución de los socios y no a la integridad del fenómeno que implica cubrir espacios que el Estado no ha cubierto o por lo menos no de esa manera. Por otro lado, garantiza fuentes de empleo estable, y retribución justa y equitativa al trabajo.

Las cooperativas no agropecuarias cubanas —al igual que muchas en el planeta- se sustentan en el trabajo de los socios, o sea, responden a la estructura de las llamadas cooperativas de trabajo asociado ${ }^{16}$,

14 REYES LAVEGA, S.: "Las especiales características de las cooperativas». Fundación Friedrich Ebert, República Dominicana, 2012. p. 1.

15 Cfr. Artículo 2.2 Decreto Ley 366 «De las Cooperativas No Agropecuarias». Gaceta Oficial No. 63 Ordinaria de 30 de agosto de 2019.

16 Las cooperativas de trabajo son cooperativas cuyo objeto social consiste en bridar ocupación a sus socios. Todos los socios trabajan en ella y, en principio, solamente ellos. Su actividad específica puede consistir en producir bienes o bridar servicios. CRACOGNA, D.: «Aspectos jurídicos de las cooperativas de trabajo en América Latina». Boletín de la Asociación Internacional de Derecho Cooperativo No. 33, 1999. p. 13. 
es decir no se reconoce a los llamados socios colaboradores o inversionistas, pues un requisito indispensable en las mismas es que el socio tiene que trabajar, sea en el objeto social fundamental o en labores de apoyo o secundarias. La única distinción que podrá existir entre los mismos es por el momento en que ingresan a la cooperativa o por la calidad y cantidad del trabajo desarrollado.

Tal como quedó explícito, las cooperativas pueden relevar al Estado en la administración de aquellas actividades económicas, productivas o de servicios que no se consideren principales, y no solo en estas, sino también como apoyo a aquellas que el Estado no pude cubrir de manera suficiente o aun haciéndolo no con la calidad que se espera. Esto último ha implicado que se creen cooperativas a partir del patrimonio estatal o a partir de una empresa estatal, las llamadas cooperativas inducidas. En estas el proceso asociativo es inverso pues el interés no nace normalmente de los futuros socios sino de un tercero que desde fuera posee ese interés. Es necesario, por tanto, una labor de educación y sensibilización, que logre la conjugación de los intereses estatales a los particulares, de otra manera el proceso se desvirtúa y la cooperativa puede perecer antes de nacer.

En tales cooperativas, los medios de trabajo, no son propiedad de esta sino del Estado, pero al decir de PIÑEIRO HARNECKER ${ }^{17}$ «lo que caracteriza una cooperativa no es la medida en que los medios de producción sean propiedad legal de la cooperativa, es decir, del colectivo de personas que sean sus miembros. De hecho, los medios de producción de una cooperativa pueden ser propiedad legal de entidades externas -incluso de algunos de sus miembros - que decidan arrendárselos a la cooperativa». Por tanto, lo importante no es quién es el propietario legal de los medios de producción (asumiendo que esté dispuesto a arrendárselos en términos razonables y de forma estable), sino que el colectivo de trabajadores pueda disponer de ellos, mediante una gestión realmente democrática; sin embargo, esta disposición incide en términos de eficiencia económica.

Este particular tipo de cooperativas se reconoce explícitamente en el artículo 12.2 del propio Decreto Ley. ${ }^{18}$

Otro tema vital en el análisis de las cooperativas son los principios en los cuales se ampara. La Declaración de Identidad Cooperativa aprobada en Manchester 1995, reconoce que las mismas se sustentan en los siguientes: Membresía Abierta y Voluntaria, Control Democrático

17 PIÑEIRO HARNECKER, C.: «Cooperativas y socialismo: una mirada desde Cuba». Editorial Caminos, La Habana, 2011 p. 34.

18 Cfr. Art. 12.2. Decreto Ley 366 «De las Cooperativas No Agropecuarias»... 
de los Miembros, Participación Económica de los Miembros, Autonomía e Independencia, Educación, Formación e Información, Cooperación entre Cooperativas, y Compromiso con la Comunidad.

Los principios cooperativos constituyen reglas que organizan y distinguen a las cooperativas, lo que se corrobora en la propia existencia de las cooperativas, su relación con otras cooperativas, el Estado, organizaciones, la comunidad, los socios, etc. ${ }^{19}$ El cumplimiento de los mismos permite evaluar el apego o no de una cooperativa a su naturaleza y concepción.

Los principios para las cooperativas no agropecuarias en Cuba se corresponden en gran medida con los postulados aprobados por la $\mathrm{ACl}$, estos son: la voluntariedad, cooperación y ayuda mutuas, decisión colectiva e igualdad de derechos de los socios, autonomía y sustentabilidad económicas, disciplina cooperativista, responsabilidad social, contribución al desarrollo planificado de la economía y al bienestar de los socios y sus familiares, colaboración y cooperación entre cooperativas y otras entidades, y educación y formación. ${ }^{20}$

Dichos principios poseen una relevancia no solo teórico-normativa sino también práctica pues garantizan el cumplimiento de los fines cooperativos, sea en relación a los socios o al colectivo en general. A continuación, se esbozan cada uno de ellos y su trascendencia a la consecución de los fines.

1. Voluntariedad: este significa que la entrada y salida del socio es libre, no está sujeta a condicionamientos externos. Sin embargo, dicho principio está moldeado por el propio objeto social cooperativo y la voluntad de la mayoría. Primero porque no debe pertenecer a una entidad de este tipo una persona que no pueda trabajar de acuerdo a la actividad que realiza ${ }^{21}$ y segundo dicha entrada debe ser aprobada por la Asamblea General $^{22}$ de la cooperativa. Aquí se manifiesta la necesaria imbricación que ha de existir entre democracia cooperativistavoluntariedad. Es necesario hacer notar que tal como se apuntaba antes en las cooperativas inducidas debe conjugarse el interés externo con el de los futuros socios pues de no ser así no se constituirá una verdadera cooperativa. En sentido general la

19 CAMPOS PÉREZ, Y.: «El capital social cooperativo como manifestación del principio de participación económica. Análisis teórico-legal en Cuba». Boletín de la Asociación Internacional de Derecho Cooperativo, Núm. 53, Bilbao, 2018. p. 174.

20 Cfr. Art. 6 Decreto Ley 366 «De las Cooperativas No Agropecuarias»...

21 Cfr. Art. 21 Decreto Ley 366 «De las Cooperativas No Agropecuarias»...

22 Cfr. Art. 24.1. Decreto Ley 366 «De las Cooperativas No Agropecuarias»... 
voluntariedad presupone la existencia de la voluntad de cooperar, de contribuir a satisfacer las propias necesidades, pero también las de la colectividad y de la sociedad.

2. Cooperación y ayuda mutuas: como consecuencia de la voluntariedad, la cooperación y ayuda mutuas supone el interés por trabajar unidos y cumplir las metas trazadas. Este principio refuerza la idea por fortificar la cultura de la cooperación, y no responder a intereses aislados. De hecho, cuando nace la voluntad de asociarse se hace para alcanzar metas que de manera individual no se alcanzarían o por lo menos no a ese nivel.

3. Decisión colectiva e igualdad de derechos de los socios: esto se traduce, en esencia, en que el máximo órgano social es la Asamblea General, en el seno de esta se toman las decisiones de mayor relevancia. En las pequeñas cooperativas esto no es un problema, sin embargo, en las que se integran por un gran número de socios es un reto importante pues sería poco operativo reunir a los asociados cada vez que sea necesario adoptar una decisión relevante. De ahí que sea necesario el control democrático en las pequeñas y más en las grandes cooperativas, de esta manera los directivos han de rendir cuenta de su gestión ante todos y responder por tales actos.

En Cuba no se enuncia como principio - la $\mathrm{ACl}$ lo incluye en el numeral segundo23 - aunque sí se norma entre los órganos sociales a la Comisión de Control y Fiscalización ${ }^{24}$ la que tendrá la facultad de verificar todos los recursos de la cooperativa y el funcionamiento de la misma, los miembros de esta pueden ser revocados por la Asamblea General ${ }^{25}$.

Por último establecer que en las cooperativas los socios tienen iguales derechos y obligaciones, es decir, las cooperativas son entidades intuito personae no pecuniae, en ellas el patrimonio tiene un fin instrumental. En estas no importa cuál es el aporte

23 La Declaración de Identidad Cooperativa, 1995, reconoce como segundo principio: Control Democrático de los Miembros. Las cooperativas son organizaciones democráticas controladas por sus miembros quienes participan activamente en la definición de las políticas y en la toma de decisiones. Los hombres y mujeres elegidos para representar a su cooperativa responden ante los miembros. En las cooperativas de base los miembros tienen igual derecho de voto (un miembro, un voto), mientras en las cooperativas de otros niveles también se organizan con procedimientos democráticos.

24 También puede descansar esta responsabilidad en un solo socio.

25 Cfr. Art. 34. Decreto 356 «Reglamento de las Cooperativas No Agropecuarias». Gaceta Oficial No. 63 Ordinaria de 30 de agosto de 2019. 
económico que estos realizan, los derechos son los mismos, un socio un voto.

4. Autonomía y sustentabilidad económicas: la autonomía parte de la personalidad jurídica, se alcanza — generalmente - con la inscripción en el registro correspondiente, en el caso de Cuba el Registro Mercantil. En un sentido jurídico significa que la cooperativa es poseedora de derechos y obligaciones, diferente de los socios y órganos que la integran. En sentido práctico posee igualmente una notable relevancia puesto que se traduce en el hecho de que la cooperativa es libre para adoptar sus propias decisiones, es independiente en su funcionamiento. Basta recordar que siempre existen determinados límites a esta autonomía, los cuales han de ser delimitados por la ley, en los marcos que esta establezca.

Es importante destacar que de vulnerarse este principio se afectaría sobremanera la identidad cooperativa pues afectaría otros principios como la voluntariedad, la gestión y control democrático, etc.

Como consecuencia de la autonomía se desprende la sustentabilidad económica, esta última no es otra cosa que la propia autonomía, pero en materia económica. Es necesario aclarar que la sustentabilidad es consecuencia de la autonomía, no obstante, esta última no se reduce solo a la materia económica, sino que trasciende a toda la gestión social, por ejemplo, a la elección de los directivos de la cooperativa. Por tanto, la norma cubana es reduccionista a la hora de establecer este principio, esto deberá ser suplido por actividades de educación y formación que delimiten el alcance de este principio.

5. Disciplina cooperativista: este principio se refiere al respeto por parte de todos los socios de las disposiciones internas, estatutarias o acuerdos sociales. Esto es un mecanismo de salvaguarda de la existencia cooperativa, pues de lo contrario si no se respetan las normas internas se trasgrede la esencia de la organización. Las cooperativas delimitan en sus estatutos las consecuencias del irrespeto de tales normas, las que puede ocasionar hasta la pérdida de la condición de socio.

6. Responsabilidad social, contribución al desarrollo planificado de la economía y al bienestar de los socios y sus familiares: este principio posee una trascendencia notable para el tema que nos ocupa pues refuerza los fines de la cooperativa. La misma ha de satisfacer intereses individuales, colectivos, y también sociales, un verdadero reto para cualquier entidad de este tipo, máximo 
cuando tales intereses no son meramente económicos sino culturales, morales, ambientales, etc.

En el caso de la contribución económica se logra desde la retribución a los socios de acuerdo al trabajo realizado hasta el pago de tributos contribuyendo a satisfacer el gasto público.

Cuando la contribución es de tipo no económica el tema es aún más complejo pues cómo medir la contribución cultural, ambiental de una cooperativa, cómo medir el alcance de estas gestiones, cómo delimitar la contribución de esta en fomentar la cultura cooperativista. Pese a tales complicaciones hoy se implementan por algunas cooperativas instrumentos para medir el alcance de tales gestiones.

7. Colaboración y cooperación entre cooperativas y otras entidades: La cooperación alcanza niveles aún mayores pues no se limita a lo interno sino entre entidades de personalidad jurídica distinta, pueden pertenecer al propio sistema cooperativo o responder a naturaleza jurídica diversa como empresas estatales, asociaciones, unidades presupuestadas, fundaciones, sociedades mercantiles, etc. Es de notar que en el caso cubano aún no existe un ente propiamente cooperativo que facilite la cooperación entre dichas entidades, por lo que resultaría sumamente necesario la creación del mismo que además de facilitar tales gestiones contribuiría a fomentarlas y aún más importante en fomentar la cooperación.

8. Educación y formación: para algunos la regla de oro del cooperativismo pues no solo se refiere a la necesaria instrucción y capacitación que han de tener los socios en torno a la actividad que realizan dentro de la cooperativa, sino en la educación en los principios del cooperativismo.

Esto último es lo más importante pues es necesario el conocimiento y configuración de los mismos no solo entre los miembros sino también en los aspirantes a socios para que de esta manera conozcan la identidad cooperativa y no desvirtúen su especial naturaleza. Cuando la educación falla, posiblemente no se respeten los otros principios, y consecuentemente tampoco el funcionamiento y gestión de la cooperativa.

Ahora bien, desde las normas jurídicas, se promueve y fomenta la creación y desarrollo de las CNoA, pero su implementación no ha sido uniforme ni en tiempo ni espacio. Las cifras muestran que el sector cooperativo no agropecuario al cierre de 2018 contaba con 434 cooperativas. En la Figura 1 se aprecia el incremento sucesivo en el total de 
cooperativas hasta el 2017 - a cuatro años de constituidas-, luego se expresa un mínimo decrecimiento. Esto acontece a que, desde su creación a la fecha, el sector cooperativo no agropecuario muestra inestabilidad al enfrentarse a la desintegración y creación de cooperativas en el período 2013-2018. De 498 cooperativas autorizadas por el Consejo de Ministros de la República de Cuba, sólo 398 se encuentran operando, 56 no están constituidas y 44 están extinguidas o en proceso de extinción ${ }^{26}$.

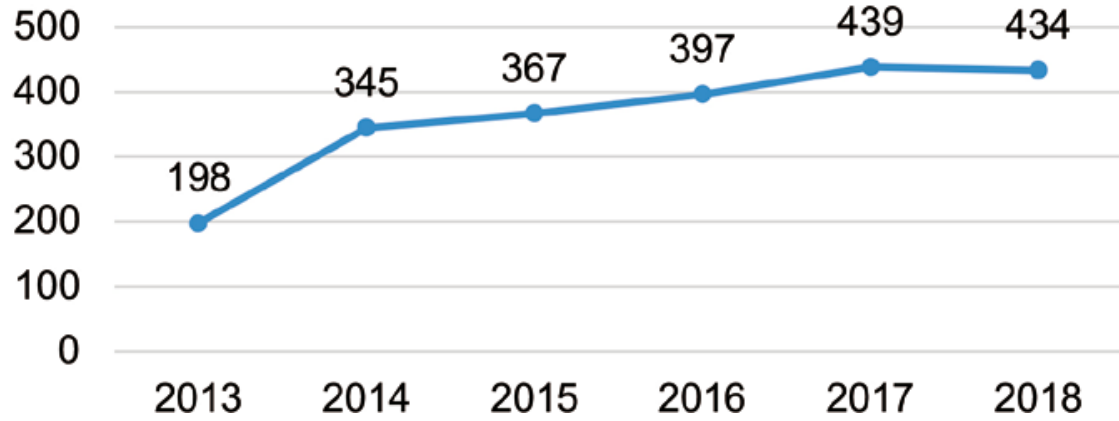

Fuente: elaboración propia a partir del Anuario Estadístico de Cuba 2018, Edición 2019.

Figura 1. Cantidad de CNoA por año en Cuba

Este comportamiento se relaciona con la forma en la que el país proyectó el proceso de creación y funcionamiento de las CNoA, el cual se previó en cuatro etapas (Figura 2). Las etapas muestran que la política del país en relación al sector cooperativo no agropecuario se encuentra en un proceso de consolidación a partir del trabajo y los resultados alcanzados durante los siete años anteriores. Ello implica el perfeccionamiento de su gestión, incrementar el impacto en las actividades que desarrollan a escala territorial y fortalecer los mecanismos de seguimiento y control requeridos para su correcto funcionamiento ${ }^{27}$, a lo que debe agregarse el fortalecimiento de la educación cooperativa.

26 MINISTERIO DE ECONOMÍA Y PLANIFICACIÓN: Perfeccionamiento del proceso experimental de la creación de cooperativas en sectores no agropecuarios. Seminario Nacional, La Habana, 2019, p. 5.

27 MINISTERIO DE ECONOMÍA Y PLANIFICACIÓN.: Perfeccionamiento del proceso experimental de la creación de cooperativas en sectores no agropecuarios. Seminario Nacional, La Habana, 2019, p. 4. 


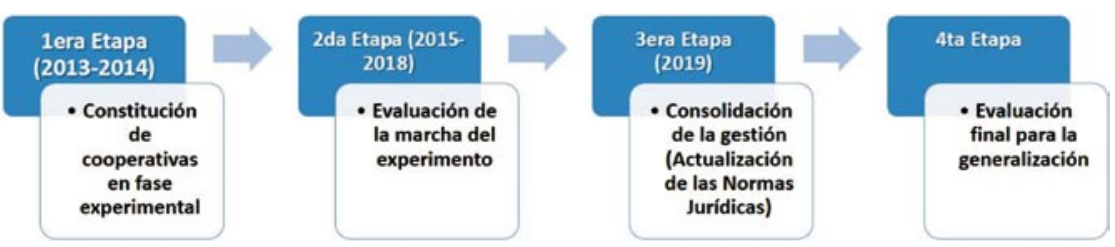

Fuente: elaboración propia a partir de los datos ofrecidos en el Seminario Nacional «Perfeccionamiento del proceso experimental de la creación de cooperativas en sectores no agropecuarios», La Habana, 2019.

Figura 2. Etapas del proceso experimental de creación y funcionamiento de CNoA

El cooperativismo no agropecuario ha sido un fenómeno del Occidente del país, se concentra (86\%) en estas provincias: Pinar del Río (12); Artemisa (68); La Habana (260); Mayabeque (14); Matanzas (19). A pesar de estos avatares el sector cooperativo no agropecuario muestra impactos desde el punto de vista socioeconómico. En tal sentido se desarrolla en 11 sectores: Gastronomía (151), Comercio (81), Construcción (59), Industria (34), Servicios personales y técnicos (29), Ornitología (17), Transporte (12), Alimentos (3); Energía (7), Servicios Contables (5) y Pesca (5), Ciencia e innovación tecnológica (1) y Otras actividades de servicios comunales de asociaciones y personales (30). Responden en su mayoría $(77,6 \%)$ a cinco órganos de relación o entidades autorizantes: Consejo de la Administración Provincial (CAP) La Habana (163); Ministerio de la Construcción (67); CAP Artemisa (60); Ministerio de la Industria (28); Ministerio del Turismo (19)28.

Luego de analizados cada uno de los principios, fines, definición y datos generales de las CNoA en Cuba se refuerza la pertinencia de las mismas en nuestro contexto, pero también los retos teórico-prácticos, que desde, lo socioeconómico y jurídico estas enfrentan, pues el camino de la verdadera cooperación no está exento de contratiempos solo que en la voluntad de superarlos debe estar el fin del cooperativismo.

\section{Huellas y desafíos socioeconómicos de las CNoA}

Hace más de ocho años, antes de que surgieran las primeras CNoA, numerosos especialistas de múltiples ciencias pronosticaron favora-

28 Datos construidos a partir del Anuarios Estadístico de Cuba 2018, Edición 2019 y los datos ofrecidos en el Seminario Nacional «Perfeccionamiento del proceso experimental de la creación de cooperativas en sectores no agropecuarios», La Habana, 2019. 
bles efectos de la implementación del cooperativismo no agropecuario en Cuba; tanto en el orden primario de lo económico y organizacional como cultural y social, entre los que se encuentran: «...elevar el nivel y calidad de vida de la población, a partir del incremento sostenido de los niveles de eficiencia y eficacia, aumentando los ingresos al presupuesto y al mismo tiempo descargarse de una gran cantidad de gastos que hoy enfrenta... puede contribuir al aumento y calidad de los servicios que se presten y/o de la actividad productiva que se realice, a partir de un control más efectivo de los recursos y contribuyendo a desarrollar el sentido de pertenencia... crear nuevas fuentes de empleo. Fortalecer la base socioeconómica del modelo económico socialista... promoverá altos niveles de eficiencia económica, productiva y social» 29 .

Otros apostaron porque las CNoA contribuyeran a la solución de la crisis en la economía informal o pequeña producción mercantil, a una nueva cultura del trabajo colectivo, a la participación, la cooperación e implicación de cooperativistas y beneficiarios. ${ }^{30}$ En general, se coincidió en que: «Su impacto en la actualización del modelo económico que se lleva a cabo en Cuba... se convierte en una vía para el desarrollo del país...». ${ }^{31}$ Sin embargo, a más de cinco años de las primeras CNoA constituidas, se pueden reafirmar los pronósticos, parcialmente, comprobados y la presencia de cuatro criterios básicos que condicionan el análisis de las CNoA: el origen, la territorialidad, el tipo de objeto social $^{32}$ y la formación profesional predominante de sus socios.

Con ello, se identifica la heterogeneidad como primera huella organizacional del cooperativismo no agropecuario, que impide conclusiones cerradas a un criterio u otro. Si las CNoA originadas de extintas empresas estatales tienen connotaciones diferentes a las CNoA creadas por la voluntariedad de algún grupo social, al interior de esta tipología,

29 RIVERA RODRÍGUEZ, C. A.; LABRADOR MACHÍN, O.; y ALFONSO ALEMÁN, J. L.: «Retos del cooperativismo como alternativa de desarrollo ante la crisis global. Su papel en el modelo económico cubano», En: Piñeiro Harnecker, C. (Comp.), Cooperativas y socialismo. Una mirada desde Cuba, Editorial Caminos, La Habana, 2011, pp. 413-414.

30 DONÉSTEVEZ SÁNCHEZ, G. M., GARCÍA RUIZ, J., FAJARDO NÁPOLES, L., FIGUERAS MATOS, D., MUÑOZ ALFONSO, Y., y MARTINERA HERNÁNDEZ, J. F.: «El nuevo cooperativismo en la Cuba del siglo XXI», En: Muñoz González, R., Donéstevez Sánchez, G. M., García Ruiz, J. (Comp.), Desarrollo y cooperativismo. Desafíos al modelo cubano de transición al socialismo, Editorial Caminos, La Habana, 2014, p. 208.

31 SANZ LARA, A.: "Las cooperativas no agropecuarias en Cuba en el contexto de transformación de la Cuba de hoy. Desafíos actuales», XII Congreso Nacional de Estudios del Trabajo, Buenos Aires, 2015. Disponible en: https://www.aset.org.ar/2015/ ponencias/11_Sanz.pdf, p.12.

32 Para conocer el objeto y localización de las CNoA creadas hasta el 2014 puede consultarse a Vuotto (2016). 
adquieren un impacto distinto las ubicadas en La Habana del resto del país o las situadas en el centro de una cabecera provincial de las que están en el medio rural, aunque sean de un mismo tipo de objeto social. A partir de tales criterios, las CNoA manifiestan variabilidad en la percepción y contribución de su responsabilidad social.

En este sentido, la percepción de la responsabilidad social de las CNoA se manifiesta en diversas posiciones que van desde la negación o devaluación de su tributo social, la ejecución por obligatoriedad o demanda, la imitación del cooperativismo agropecuario o la concientización pertinente. Sin duda, la negación, la obligatoriedad y la imitación de la responsabilidad social, en medida gradual, constituyen expresiones contradictorias del cooperativismo como movimiento social y síntomas de una apremiante educación cooperativa. Tal variabilidad provoca múltiples huellas sociales que dependen del estudio de caso seleccionado. No es interés, encasillar en una u otra CNoA, sino en abordar la generalidad de las huellas recogidas en estudios recientes.

Los principios del cooperativismo enfatizan la responsabilidad social que debe existir no solo hacia lo interno de la organización, sino sobre todo hacia su proyección externa. Algunas CNoA se escudan o justifican la falta de responsabilidad social, porque la asocian a la sustitución del rol gubernamental; por lo que se reduce la responsabilidad social al cumplimiento de las necesidades sociales de sus socios. Esta lamentable tendencia solo conlleva a un falso cooperativismo, con pérdida de sentido, que socava el proceso de implementación en un proceso de transformación o mutación de cooperativismo a pequeña o mediana empresa. El cooperativismo es un movimiento sensible de conversión cuando uno de sus principios básicos se quebranta; de ahí que está en constante riesgo de pérdida de identidad y bajo el patrón comparativo con las empresas estatales o con las pequeñas y medianas empresas, de carácter privado.

Las huellas sociales del cooperativismo no agropecuario, se sintetizan en acciones, en algunos casos denominados programas, de corte: educacional, dirigido al mejoramiento constructivo de las escuelas y hogares de niños sin amparo familiar, también sufragan gastos de edición de textos; de salud, enfocado a donación de sangre y mantenimiento integral de consultorios médicos rurales y urbanos; de comunicación, diseñado para la confección de un modelo integrativo que optimiza la información y el conocimiento sobre la imagen cooperativa hacia la sociedad; de atención a socios y sus familiares, encaminado a actividades de apoyo constructivo y social, recreativas y culturales con los socios, las familias, clientes, la comunidad - posteriormente se profundizará este aspecto-; y medioambiental, orientado al compromiso de no de- 
forestar, ni contaminar los ríos o botar basura, así como la conservación, buen manejo de los recursos, promover la educación ambiental y velar por la calidad de vida y el entorno.

Un reto importante referido a la responsabilidad social y a la consolidación de la impronta acaecida, consiste en la búsqueda y aplicación de un instrumental de gestión que garantice la óptima disposición de los recursos y estrategias de desarrollo social pertinentes con el recurso humano, su familia, su comunidad y la sociedad. ${ }^{33}$ Al mismo tiempo, se requiere, como desafío, la necesidad de expandir e implementar un modelo de gestión social que le permita medir con más efectividad el impacto en los asociados, familias, comunidad y sociedad. ${ }^{34}$ El Modelo de Balance Social Cooperativo (MBSC) constituye una experiencia acertada con sus méritos y defectos que aporta significativos indicadores y resultados cualitativos y cuantitativos de autoevaluación, en lo referente a los principios cooperativos, la eficiencia económica-productiva, las relaciones de género y el compromiso medioambiental ${ }^{35}$.

No obstante, a pesar de los logros, en general, se denota en las CNoA un énfasis hacia el logro económico en detrimento de los valores cooperativos de solidaridad, responsabilidad social, cooperación entre los socios.

Las cifras oficiales indican que las CNoA constituyen fuente de empleo e ingresos para alrededor de 18 mil asociados, de ellos 3 mil mujeres (Figura 3), además de generar empleo en 2018 para 777 trabajadores contratados. Estas cifras en asociados, representan el 0,4\% de los ocupados en el país y de la población económicamente activa y el $3,9 \%$ de los ocupados en el sector cooperativo a nivel nacional. Mientras que en relación al sector no estatal, los ocupados en las CNoA representan el 1,3\% de los ocupados. A pesar de que las cifras manejadas muestran a las cooperativas como fuentes de empleo en muchos

33 ALFONSO ALEMÁN, J.: "Responsabilidad, gestión y balance social en las empresas cooperativas», Cooperativismo y Desarrollo, vol. 1, núm. 2, 2013, pp. 186-198. Disponible en http://coodes.upr.edu.cu/index.php/coodes/article/view/ 61 /173

34 MONTENEGRO MORALES, M.: «Experiencias de buenas prácticas en la Cooperativa No Agropecuaria de Servicios de Construcción, Andamios y Cofres», Cooperativismo y Desarrollo (COODES), vol. 6, núm. 1, enero/junio de 2018, pp. 108-119. Disponible en: http://coodes.upr.edu.cu/index.php/coodes/ article/view/192

35 SOTO ALEMAN, L.; GONZÁLEZ FERRER, Y.; LLANES GUERRA, O.: «El Balance Social Cooperativo en Cuba: Estado de la cuestión», En: Schujman, M S., Iturraspe Oviedo, F., Fajardo García, I G., Chaves Gaudio, R.: La participación de los asociados en las entidades de la economía social y solidaria. Cooperativas de trabajo asociado. Autogestión. Carta del trabajador autogestionario. Investigación: La participación de los Asociados en las entidades de la Economía Social y Solidaria, Editorial de la Universidad Nacional de Rosario, Argentina, 2019. pp. 46-69. 
sectores, en algunos casos se tienden a la no incorporación de nuevos socios a la organización. Esto producto a cuatro razones esenciales: la manera en que se organiza el trabajo; la demanda del producto o servicio; el poco interés por compartir con más personas las utilidades alcanzadas y en último lugar, porque a mayor cantidad de asociados más difícil es el control de la eficiencia y calidad del trabajo aportado.

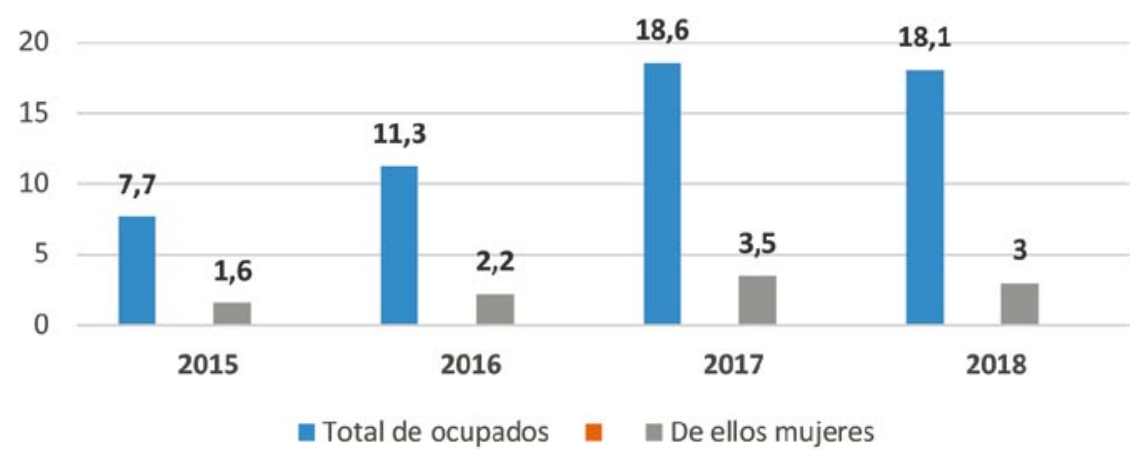

Fuente: elaboración propia a partir del Anuario estadístico de Cuba 2018, Edición 2019.

Figura 3. Ocupados de las CNoA de 2015 a 2018 en Cuba

En términos de ingresos el sector avanza. Los mismos ascienden a más de 6 mil millones de pesos. Además ha contribuido satisfactoriamente al bienestar de los asociados. En el año 2018 el anticipo promedio mensual ascendía a 5.193 dólares, lo que significa que el sector cooperativo no agropecuario superó en 4.416 dólares el salario medio de Cuba ${ }^{36}$.

En relación al perfeccionamiento de la actividad que realiza y de la organización del trabajo, las experiencias muestran que las nuevas cooperativas en su mayoría han mejorado los servicios, sobre todo las cooperativas en las actividades de la gastronomía, la contabilidad y el transporte. Si se hace un análisis del último caso, las cifras muestran un incremento considerable de la transportación de pasajeros por concepto de cooperativas en el sector. En el 2013 las cooperativas transportaron alrededor de 2 millones 800 mil pasajeros y para el 2018 las

36 MINISTERIO DE ECONOMÍA Y PLANIFICACIÓN: «Perfeccionamiento del proceso experimental de la creación de cooperativas en sectores no agropecuarios». Seminario Nacional «Perfeccionamiento del proceso experimental de la creación de cooperativas en sectores no agropecuarios», La Habana, 2019. 
cifras ascendían a 18 millones 300 mil pasajeros lo que representa el $0,86 \%$ de los pasajeros transportados en el país en ese año ${ }^{37}$.

En relación a la organización del trabajo, las experiencias muestran que tiende a ser colectivo, en lo que se considera esencial: a) la experiencia laboral - tiempo dedicado o experiencia en la actividad productiva o de servicios, ejercicio de la contabilidad o capacidad de gestión o dirección-; b) la capacidad de solucionar problemas —reparación de equipos, atención al cliente, ayuda mutua en la realización de tareas-; b) disposición de los directivos. Este último aspecto evidencia centralización en la toma de decisiones, pues se aplica la democracia representativa en la organización cooperativa. El asociado le atribuye a la Administración, poder y confianza para gestionar y facilitar los procesos, aunque incluso, en determinados casos se va más allá de lo aprobado por la Asamblea General. De ahí deriva uno de los retos del cooperativismo, que se refiere al logro de la gestión horizontal, descentralizada y creativa en la cual se impliquen los asociados. ${ }^{38} \mathrm{~A}$ pesar de ello, la forma general de distribución de las utilidades se muestra de una manera más equitativa. Aún cuando algunas cooperativas aplican, erróneamente, el principio de igualitarismo, otras son capaces de establecer criterios para la distribución de las utilidades de acuerdo a la «capacidad, agilidad, habilidades» lo que diferencia la obtención del beneficio.

Otra de las huellas que ha dejado el cooperativismo no agropecuario se refiere a su razón de ser, su contribución al bienestar social de los socios y sus familias. Entre las formas más comunes se encuentran: la distribución del anticipo a cuenta de utilidades, al cual nos referimos anteriormente; apoyo financiero a los socios con problemas de enfermedad; reparación de viviendas; estimulación moral en las asambleas por los resultados obtenidos; visita a centros históricos; actividades culturales y recreativas; atención financiera a los jubilados con bajos ingresos y especialmente las acciones de capacitación o educación.

En este último aspecto es necesario aclarar que este más que un principio cooperativo constituye una responsabilidad de la organización en dos sentidos esencialmente: 1) Desde el punto de vista de sosteniblidad de la organización - a decir, la educación en los principios y valores del cooperativismo y 2 ) desde la sostenibilidad productiva- a decir, la trasmisión en las nuevas generaciones y asociados a la cultura em-

37 Anuario 2018, edición, 2019.

38 ALTUNA GABILOND, L.; LOYOLA IDIAKEZ, A.; PAGALDAY TRICIO, E.: "Mondragón: los dilemas de un cooperativismo maduro», En: PIÑEIRO HARNECKER, C.: "Cooperativas y socialismo: una mirada desde Cuba». Editorial Caminos, La Habana, 2011 p. 215. 
presarial. En este caso se encuentran varias diferencias. Este aspecto, incluido en la nueva legislación, no es reconocido y potenciado por todas las CNoA con la misma fuerza. Podría decirse que tienen relación con la precedente cultura cooperativa, antes del momento de constitución de la organización; con la intención de la organización, ya creada, por perfeccionar su proceso productivo y de servicios y el funcionamiento como cooperativa verdaderamente. De ahí que Cuba cuente con CNoA que no realizan acciones de educación, otras que espera recibirla de agentes externos y algunas — muy escasas - que además de recibir de agentes externos, son capaces de crear sus propias iniciativas a partir del conocimiento de sus asociados. Pudiera citarse la creación de cursos para familiares de los asociados sin vínculo laboral, procesos de categorización de los asociados así como el interés en la formación integral, profesional y la superación de los asociados.

Estos aspectos están relacionados con el apoyo que brindan las cooperativas a las comunidades y centros de salud y educación. Estas acciones son muy reconocidas y valoradas por la población que es beneficiaria. Es muy difícil contabilizar este tipo de acciones; pues aunque las CNoA logran medir en dineros lo que significaron las acciones realizadas, las fuentes estadísticas oficiales no las registran.

Pocos autores reconocen huellas comunes y positivas como la unión, la motivación, el trabajo en equipo y cierta mejora en la participación. 3940 Es precisamente, la participación, un desafío, por ser una de las dimensiones del cooperativismo no agropecuario más cuestionadas, porque fluctúa entre impactos sociales positivos y negativos, de acuerdo a los cuatro criterios analíticos. SUÁrez evidenció el desconocimiento en los socios sobre el funcionamiento de esta modalidad de gestión ${ }^{41}$. Henríquez arrojó que no se aplicaba la participación democrática de los socios, sino que se reproducían lógicas estatales

39 VUOTTO, M.: «Las cooperativas no agropecuarias y la transformación económica: políticas, procesos y estrategias», REVESCO, núm. 120, enero/abril 2016, pp. 149-181. Disponible en https://www.researchgate.net/ publication/282467022_Las_cooperativas_no_agropecuarias_y_la_transformacion_economica_en_Cuba_politicas_procesos_y_ estrategias

40 PINO SANTOS, P. C. H.: «Una mirada internacional y nacional a las investigaciones sobre participación en la gestión cooperativa», Alternativas cubanas en Psicología, vol. 6, núm. 16, enero/abril 2018, pp. 23-35. Disponible en https://www. acupsi.org/articulo/209/una-mirada-internacional-y-nacional-a-las-investigaciones-sobreparticipacin-en-la-gestin-cooperativa.html

41 SUÁREZ, Y.: "La responsabilidad social de las cooperativas urbanas y su contribución al desarrollo local en el municipio Centro Habana» (tesis de diploma), Departamento de Sociología, Universidad de La Habana, Cuba, 2014, p. 88. 
aprendidas ${ }^{42}$. Varias autoras ${ }^{43}$ constataron inconsistencias referentes al proceso participativo en los documentos legales que sustentan jurídicamente a las CNoA. Piñeiro, Pérez, Reinoso, Padrón, y Hernández; 44 SuÁREZ $^{45}$; TERRY ${ }^{46 ;}$ y Henríquez ${ }^{47}$ consideran la educación cooperativa una de las condicionantes primordiales para una adecuada participación democrática.

La falta de educación cooperativa se establece como un eje central reiterado en las diversas limitaciones encontradas y deficiente en los estudios realizados. La exigua capacitación influye en el desconocimiento de los principios cooperativos y sobre el paradigma de gestión cooperativa, no solo de los socios, sino de las instituciones gubernamentales vinculadas a las CNoA. Lo que se convierte en un ciclo de influencias, pues la poca capacitación está dada, en gran parte, por el pobre apoyo de tales instituciones gubernamentales y la débil cultura cooperativa. 48 Otros autores, incorporan al análisis la falta de comunicación efectiva, por parte de las cooperativas y los gobiernos locales. ${ }^{49}$ Cada una de las categorías enunciadas: educación, cultura, identidad, comunicación, gestión, intercooperación son partes de un ciclo de influencias estrecho y sistémico.

Sin duda, la débil cultura cooperativa es causa y efecto, de la falta de educación cooperativa, del limitado apoyo gubernamental y de un deteriorado sentido de pertenencia. La huella socioeconómica del cooperativismo no agropecuario no ha podido ahondar en lo referido a cultura y educación cooperativas, sentido de pertenencia, así como intercooperación y comunicación efectiva entre sociedad y CNoA; aunque no se desechan avances leves en experiencias y buenas prácticas

42 HENRÍQUEZ, P.: «La participación en la gestión administrativa de la CNA Confecciones Model: un estudio de caso» (tesis de maestría), Departamento de Sociología, Universidad de La Habana, Cuba, 2017, p. 112.

43 Entre estas autoras pueden señalarse a: HENRÍQUEZ, P.: "La participación..., SUÁREZ, Y.: "La responsabilidad social...», TERRY, Y.: "Relaciones socioeconómicas en los mercados cooperativos del municipio Plaza de la Revolución» (tesis de diploma), Departamento de Sociología, Universidad de La Habana, Cuba, 2016, p. 94.

44 PIÑEIRO, C.; PÉREZ, D.; REINOSO, O.; PADRÓN, N., y HERNÁNDEZ, M.: «Reporte de investigación de cooperativas no agropecuarias. Informe del Centro de Estudios de la Economía Cubana», Universidad de La Habana, Cuba, 2014, p. 42.

45 SUÁREZ, Y.: «La responsabilidad social...»», p. 88.

46 TERRY, Y.: «Relaciones socioeconómicas...», p. 94.

47 HENRÍQUEZ, P.: «La participación...», p. 112.

48 Ibidem.

49 OJEDA SURIS, D.: «Las cooperativas no agropecuarias: dos años después», En: García Ruiz, J., Figueras Matos, D., y González Mastrapa, E. (Comp.). Sector cooperativo y desarrollo local (pp. 76-83), Editorial Feijóo, La Habana, 2016, p. 155. 
específicas, todavía instituyen importantes desafíos del cooperativismo no agropecuario cubano. También relacionado a ello, los especialistas pronosticaron: "Grandes retos hay que vencer para que estas nuevas formas de cooperativas en los diferentes sectores aprobados logren avanzar... y mostrar en su conjunto los resultados positivos que son necesarios en estos tiempos de transformaciones y cambios en la sociedad cubana» ${ }^{50}$.

\section{Trascendencia jurídica de la constitución de Cooperativas No Agropecuarias en Cuba}

Con la aprobación el 15 de noviembre de 2012 del Decreto Ley 305 «De las cooperativas no agropecuarias» y sus normas complementarias, se amplió jurídicamente un fenómeno que era exclusivo al sector agrario en Cuba ${ }^{51}$. Consecuencia de ello, no solo se permitió la constitución de cooperativas en sectores distintos del agrario, sino que además se fomentó dicha constitución. Según ReYES LAVEGA, criterio que compartimos, se supone que: "en cualquier país, la aprobación de una ley de cooperativas es un elemento muy importante para facilitar el desarrollo de dichas entidades. Su reconocimiento legal y la regulación clara de sus diversos aspectos no solo les pueden trazar un canal más fluido para su constitución y funcionamiento, sino que también la ley puede ser un instrumento en el cual se incluyan elementos de estímulo y fomento de sus actividades» ${ }^{52}$. Se demuestran aquí los principales derroteros de una ley de cooperativas.

Ya desde el triunfo y posterior consolidación de la Revolución Cubana se impulsó la aprobación de cooperativas, pero reducidas al sec-

50 JIMÉNEZ GUETÓN, R., y PADRÓN SÁNCHEZ, N.: «Retos de las cooperativas no agropecuarias en el contexto actual cubano», En: García Ruiz, J., Figueras Matos, D., y González Mastrapa, E. (Comp.). Sector cooperativo y desarrollo local (pp. 84-89), Editorial Feijóo, La Habana, 2016, p.89.

51 El marco jurídico de las cooperativas no agropecuarias estaba integrado esencialmente en ese momento por las siguientes normas jurídicas:

Decreto Ley No. 305, de 15 de noviembre de 2012, «De las Cooperativas No Agropecuarias» y el No. 306, de 17 de noviembre del mismo año, "Del Régimen Especial de Seguridad Social de los Socios de las Cooperativas No Agropecuarias»; Decreto No. 309, del 28 de noviembre de 2012, "Reglamento de las Cooperativas no Agropecuarias»; Resolución del Ministerio de Finanzas y Precios, No. 427 de 4 de diciembre de 2012, y otra del de Economía y Planificación, la No. 570 de 15 de noviembre de 2012. Gaceta Oficial 053 Extraordinaria de 11 de diciembre de 2012.

52 REYES LAVEGA, S.: «Aportes para una ley de cooperativas». Fundación Friedrich Ebert, República Dominicana, 2012. p 1. 
tor agrario. Antes del 2012 solo existían las Cooperativas de Crédito y Servicios (CCS), las Cooperativas de Producción Agropecuaria (CPA) y las Unidades Básicas de Producción Cooperativa (UBPC). Estas últimas aparecen en el pasado más reciente a partir de la modificación de la Constitución de 1976 en 1992.53

Entonces, el cooperativismo no agropecuario significa un reto y a la vez una oportunidad en el contexto actual cubano no solo desde el punto de vista socioeconómico sino además desde lo estrictamente jurídico.

Reto porque, desde su concepción en 2012, era necesario aprobar un marco legal propicio para estimular la constitución de cooperativas, sin embargo, este podía no ser armónico con el resto del ordenamiento jurídico precedente, sobre todo con normas de mayor rango, esencialmente con la Carta Magna.

En este orden, en la Constitución Cubana de 1976 vigente hasta el 2019 se reconocía en el artículo 20 el derecho de los agricultores pequeños a unirse a los efectos de la producción agropecuaria y de obtener créditos y servicios de parte del estado, sin embargo, esta misma posibilidad no se reconoció a otros sectores de la sociedad que igualmente forman parte de este estado de trabajadores que es Cuba tal como lo declara dicha norma en el artículo 1.54

La constitucionalidad, por tanto, de las cooperativas no agropecuarias fue objeto de no pocas controversias pues no es menos cierto que si todas son cooperativas (las agrarias y no agrícolas) no es lógico que se reconocieran expresamente a unas y no a todas. Sin embargo, para algunos estudiosos ${ }^{55}$, en lo que se incluyen los autores del presente trabajo el derecho de constituir cooperativas se incluye dentro del derecho de asociación reconocido en el artículo 54 o incluso como parte de las sociedades y asociaciones económicas que el estado reconoce en el numeral 23.

Sin embargo, es innegable y al decir de RodríGuez Musa «lo cierto es que no se conoce ningún indicio político-jurídico inequívoco de que

53 En la actualidad las normas cooperativas agrarias en Cuba también han sido modificadas en busca del perfeccionamiento de las mismas. Estas son: Decreto-Ley No. 366 «De las cooperativas agropecuarias» y Decreto No. 354 Reglamento del Decreto-Ley de las cooperativas agropecuarias. Gaceta Oficial No. 37 Ordinaria de 24 de mayo de 2019.

54 Cfr. Constitución de la República de Cuba. Gaceta Oficial Extraordinaria n. ${ }^{\circ} 7$ del 1 de agosto de 1992.

Artículo 1: Cuba es un Estado socialista de trabajadores, independiente y soberano, organizado con todos y para el bien de todos...

55 Pueden incluirse aquí a estudiosos de la Cátedra de cooperativismo de la Universidad Central Marta Abreu de las Villas, Cuba. 
el constituyente haya pretendido ofrecer un espacio a la cooperativa para que se manifestara más allá de la esfera agropecuaria. La principal y más peligrosa consecuencia de esto es que no se buscan en la Constitución las pautas y límites necesarios para entender con claridad (el legislador, las instituciones públicas, las cooperativas y la sociedad en general) su esencia, rasgos, contenido y posición al interior del sistema socioeconómico nacional, en un período trascendental para la subsistencia del socialismo». De ahí la urgencia de que su regulación constitucional sea exacta y consecuente con su identidad, que también es serlo con los propósitos humanistas que caracterizan el socialismo cubano.

Dicha cuestión es superada en la actual Constitución de la República aprobada en abril del presente año, pues la misma reconoce en el artículo 22 b) que la propiedad cooperativa es la sustentada en el trabajo colectivo de sus socios propietarios y en el ejercicio efectivo de los principios del cooperativismo. Sin embargo, aunque se reconoce como una mera forma de propiedad ya se incluyen elementos típicos de una cooperativa tal como el trabajo colectivo y el seguimiento de los principios del cooperativismo. No obstante, aún sigue siendo estrecho el hecho de reconocerlas solo como una forma de propiedad, en estas lo más importante es el factor sociológico, las relaciones de cooperación y el elemento económico uno de sus resultados.

Por otra parte, la constitución de cooperativas en sectores distintos de agropecuario es también una oportunidad pues constituye un momento propicio para tomar en cuenta las buenas experiencias que desde lo agrario existen en el país, pero conociendo también las malas prácticas para no incurrir en ellas, de esta manera contribuir al modelo genuino y armónico de cooperativismo que se aspira.

También desde lo organizacional se imponen no pocos retos pues no existen en el país órganos superiores que agrupen a las cooperativas; que las orienten y además preparen a los entes que se relacionan con estas. Puede producirse cuando no se tiene claro la identidad cooperativa un intervencionismo por parte del estado, o confusión en cuanto a la naturaleza de las cooperativas frente a otras agrupaciones sociales como es el caso de las sociedades. En fin, laceraciones a los principios que las ordenan.

Hasta el presente no se han constituido dichos órganos en Cuba, por tanto, no existe un movimiento cooperativo armónico y uniforme, dicha estructura facilitaría la relación entre cooperativas a escala nacional e incluso internacional al igual que favorecería la relación con los entes de relación. Al decir de Bellot Cases, PIÑANa López, Quiles Bodí, y Romero MARTínez «tradicionalmente, el cooperativismo siempre ha in- 
tentado fomentar el establecimiento de relaciones entre cooperativas, así como la pertenencia a organismos o entidades que defiendan y representen sus derechos» ${ }^{56}$. Por tanto, este será un vacío que ha de ser cubierto si se quiere un movimiento cooperativo coherente y dinámico.

Desde la praxis jurídica supone un reto para funcionarios públicos, abogados, asesores, jueces y fiscales que han de convivir con las cooperativas. La propia existencia de las mismas impone retos que van desde la formalización ante notario de la constitución y estatutos, la inscripción en registros, la revisión y adecuación de cuestiones procesales; estas exigen atender sus particularidades, por solo citar algunos ejemplos.

También oportunidad y reto para los propios socios, en cuanto a la trazabilidad de la gestión y destino social. Oportunidad: en tanto los estatutos y demás disposiciones internas constituyen ley que ordena y dispone. En este orden, ha significado GARCíA MüLLER, «el estatuto constituye el conjunto de normas de rango sub-legal de carácter especial contenidas en el mismo documento constitutivo o en uno posterior, que regula la organización interna, las relaciones entre los miembros y delimita la esfera de competencia, actuación y eficacia de los órganos sociales de la entidad, así como la disolución y liquidación de esta». ${ }^{57}$ Es importante señalar que se trata de normas de Derecho que se dan a sí mismos los fundadores de la entidad. Por tanto, los socios han de procurar que estos se elaboren y respeten colectivamente, además que han de incluir todas aquellas cuestiones vitales para el funcionamiento de la cooperativa. Por su parte, reto pues es necesaria la participación colectiva y democrática en su aprobación y cumplimiento que demuestre el carácter especial de las cooperativas y la no copia de modelos capitalistas de gestión.

En otro sentido es necesario destacar que la aprobación de las disposiciones jurídicas en este ámbito no solo ha permitido extender el fenómeno, sino que lo ha hecho con carácter experimental por lo que constituyen un eslabón temporal para su posterior perfeccionamiento. ${ }^{58}$

56 AA.VV.: «Las Cooperativas valencianas. Manual de Constitución y Funcionamiento». Confederación de Cooperativas de la Comunidad Valenciana, 2013, p. 64.

57 GARCÍA MÜLLER, A.: «Derecho Cooperativo, Mutual y de la Economía Social y Solidaria». Mérida. Capítulo 6, 2019, p. 1.

58 En el segundo Por Cuanto del mentado Decreto Ley 305 se establece que: En el proceso de actualización del modelo económico cubano es necesario la creación, con carácter experimental, de cooperativas en sectores no agropecuarios, lo que requiere de una norma jurídica que instrumente su creación y funcionamiento. 
En este contexto, seis años después de aprobadas las primeras normas jurídicas para las cooperativas no agrarias se han derogado estas, y así se ha actualizado el marco jurídico que reconocían.

Al decir de VeGA MATO ${ }^{59}$ el proceso experimental en su etapa de generalización, tiene como objetivos continuar avanzando escalonadamente, consolidar lo hecho y corregir los errores o desviaciones que se presentan, tanto en el funcionamiento interno de estas cooperativas como en sus relaciones con los demás actores de la economía y, a partir de ahí, emprender la generalización de las experiencias positivas.

Se han aprobado las siguientes normas jurídicas ${ }^{60}$ :

- Decreto Ley No. 366 «De las Cooperativas No Agropecuarias».

- Decreto No. 356 «Reglamento de las Cooperativas No Agropecuarias».

- Resolución No. 36 de la Ministra de Finanzas y Precios, sobre el tratamiento de precios, tributario, financiero y contable de las cooperativas no agropecuarias.

- Resolución No. 362 de la Ministra de Finanzas y Precios, respecto al pago del Impuesto sobre Ingresos Personales de los trabajadores contratados.

Este marco jurídico nuevo se concentra, en esencia, en superar las principales problemáticas que se manifiestan en las cooperativas hoy día. Al decir de la propia VEGA MATO ${ }^{61}$ persisten desviaciones en la gestión de algunas cooperativas, asociadas fundamentalmente a indisciplinas y violaciones de la legalidad, que han desvirtuado los principios del cooperativismo. Estas se materializan en: apropiación indebida de recursos e ingresos y corrupción, cooperativas que materializan una parte importante de su gestión contratando fuerza de trabajo asalariada y comprando servicios a terceros, deficiencias en los registros contables, marcadas diferencias en los anticipos percibidos por los socios que ejercen como directivos, con respecto a los que realizan labores directas en la actividad fundamental, utilización de créditos bancarios con fines diferentes a los conceptos por los que fueron otorgados, irregularidades

59 VEGA MATO, J.: Entrevista ofrecida al periódico Granma en fecha 29 de agosto de 2019 periodista Castro Morales, Y. «Nuevas normas jurídicas que actualizan y perfeccionan la legislación sobre las cooperativas no agropecuarias».

60 Las disposiciones jurídicas han sido publicadas en la Gaceta Oficial No. 63 Ordinaria de 30 de agosto de 2019.

61 VEGA MATO, J.: Entrevista ofrecida al periódico Granma en fecha 29 de agosto de 2019 periodista Castro Morales, Y. «Nuevas normas jurídicas que actualizan y perfeccionan la legislación sobre las cooperativas no agropecuarias». 
en los presupuestos de obras de la construcción y en las facturaciones y cobros, no se han materializado las transformaciones previstas en la gestión y la imagen de las cooperativas en la actividad de la gastronomía, y tendencia al incremento de precios.

Consecuencia de ello, las recientes disposiciones jurídicas persiguen poner freno a tales cuestiones, pero también consolidar un fenómeno que ha impactado positivamente en Cuba, por lo que merece ser perfeccionado. Pese a este interés aún subsisten problemáticas en el marco legal que afectan su aplicación y a las cooperativas de este tipo, ellas son:

- Laceraciones al principio de autonomía, pues tal como se dijo antes, aunque el propio Decreto Ley No. 366 «De las Cooperativas No Agropecuarias» lo reconoce como principio solo lo enfoca desde el ámbito económico. Este se materializa en la obligatoriedad de responder por sus deudas y obligaciones, sin embargo, la autonomía posee contenido y efectos mucho más abarcadores. El apoyo del Estado a las cooperativas no debe desvirtuar su autonomía. Además, la relación Estado-cooperativa debe comprenderse desde dos direcciones. La primera asociada al deber de la empresa cooperativa con las políticas gubernamentales, sobre todo estrategias de desarrollo local. La segunda asociada al papel del Estado. Este, debe propiciar espacios para la participación del sector cooperativo en las decisiones estratégicas, a través de políticas para la atención de sus intereses. También es su función fiscalizar, apoyar y asesorar la gestión cooperativa y su interrelación con los intereses locales, provinciales y nacionales ${ }^{62}$ pero respetando su autonomía.

- El procedimiento de aprobación y constitución de una cooperativa no agropecuaria en Cuba es largo y tortuoso, en este participan organismos locales y nacionales, administrativos y no (organismos de la Administración Central del Estado, Consejos de Administración Provinciales, Comisión Permanente para la Implementación y Desarrollo de los Lineamientos, Consejo de Ministros).

Este proceso desfavorece, la creación de cooperativas, pues ha resultado dilatado y engorroso, precedido de excesivos reque-

62 RIVERA RODRÍGUEZ, C. A.; LABRADOR MACHÍN, O.; y ALFONSO ALEMÁN, J. L.: «Retos del cooperativismo como alternativa de desarrollo ante la crisis global. Su papel en el modelo económico cubano», En: Piñeiro Harnecker, C. (Comp.), Cooperativas y socialismo. Una mirada desde Cuba (pp. 397-415), Editorial Caminos, La Habana, 2011, p. 420 . 
rimientos, que burocratizan el proceso y limitan la libertad de constitución y la autonomía de la voluntad a los fines de propiciar la conformación de esta forma de gestión económica socialista y con una propiedad colectivizada. ${ }^{63}$

En el presente, (2019) la Comisión de Implementación y Desarrollo de los Lineamientos ha informado que no se crearán nuevas cooperativas, la prioridad es concentrar los esfuerzos en la consolidación de las constituidas, y determinó devolver de manera oficial a los solicitantes, a través de los Consejos de la Administración Provincial, Organismos de la Administración Central del Estado y Entidades Nacionales correspondientes, todos los proyectos que se encontraban en fase de evaluación por la Comisión, hasta tanto se reanude el proceso de creación de nuevas cooperativas, una vez concluida el periodo de consolidación. No se ha establecido la duración de esta etapa.

- Se reconoce la posibilidad de aportar dinero y otros bienes y servicios por parte de los socios a las cooperativas, como parte del capital de trabajo inicial. En el caso del dinero la norma delimita que ha de formalizarse ante notario conjuntamente con la aceptación del sujeto como socio ${ }^{64}$.

Por su parte en el caso de los otros aportes se explicita que puede hacerse efectiva su aportación mediante cualquiera de los actos traslativos de dominio, gratuitos o lucrativos, reconocidos en Derecho. No reconociéndose en la misma que la aportación es distinta a cualquier acto traslativo de dominio reconocido en Derecho, pues persigue fines distintos de estos, y los efectos que genera también son diferentes. La aportación es considerada como un acto cooperativo preparatorio de los actos cooperativos estrictamente dichos. Entonces, el efecto de que sea un acto cooperativo (aunque preparatorio) es que, como tal, queda regulado en primer lugar por la normativa cooperativa, ya sea en la ley, estatuto o reglamento interno y sólo de manera supletoria por la norma genérica de la actividad. ${ }^{65}$

63 MUÑOZ ALFONSO, Y; LÓPEZ GONZÁLEZ, I; CAMPOS PÉREZ, Y.: «Las cooperativas no agropecuarias de primer grado en Cuba. Consideraciones críticas de su régimen jurídico». En Revista Jurídica de Economía Social y Cooperativa, No 32. CIRIEC, Valencia, 2018. p.142

64 Cfr. Art: 35-38 Decreto No. 356 «Reglamento de las Cooperativas No Agropecuarias».

65 CAMPOS PÉREZ, Y.: «El capital social cooperativo como manifestación del principio de participación económica. Análisis teórico-legal en Cuba». Boletín de la Asociación Internacional de Derecho Cooperativo, Núm.53, Bilbao, 2018. p. 173-205. 
- Se establecen límites máximos en el número de socios de acuerdo al tipo de cooperativas, y su integración social. ${ }^{66}$ Cuestión que contradice el propio desarrollo de la cooperativa, pues cuanto mayor sea la gestión socio-económica, mayor puede ser el número de socios que esta necesite integrar. Lo importante no es en nuestro criterio el número de socios, sino la participación real de los mismos en la consecución del objeto social.

Por otra parte, el número mínimo de socios que se exige (tres socios) ${ }^{67}$ para la constitución de una cooperativa no agropecuaria es sumamente exiguo y puede provocar la creación de una cooperativa que encubra otro tipo social como es el caso de la sociedad mercantil unipersonal. A esto se une el hecho de que para algunos cooperativistas existe confusión entre las funciones de la Asamblea, el presidente y los órganos administrativos en una cooperativa. Esta última cuestión refuerza la idea de la necesaria educación cooperativa y que acertadamente reconoce como principio la nueva legislación cooperativa cubana.

Desde el punto de vista jurídico las cooperativas han supuesto no pocos retos que se refieren a lo estrictamente legal y cooperativo, pero también a la interpretación de otras disposiciones legales y su aplicabilidad. También es necesario la instrumentación de un ente cooperativo nacional que agrupe a todas las cooperativas y armonice su gestión.

La nueva legislación cooperativa aprobada en Cuba actualiza su marco jurídico, sustentada en superar las problemáticas cooperativas demostradas, pero aún subsisten en las mismas cuestiones que afectan el funcionamiento de estas organizaciones; tal es el caso del procedimiento de constitución.

Algunos de los obstáculos que han enfrentado las cooperativas en el sector, en estos siete años, es el lento y engorroso mecanismo de aprobación de las mismas; el carácter experimental de la legislación que las ampara; limitado acceso a un mercado mayorista; desviación de la esencia cooperativa por falta de cultura cooperativa o violaciones de la legalidad; excesiva contratación de fuerza de trabajo; deficiencias en los registros contables, significativas diferencias en los anticipos percibidos por los socios y por los miembros de las Juntas Administrativas; tendencia al incremento de los precios; herencias de las insuficiencias

66 Cfr. Disposición final Tercera Decreto Ley No. 366 «De las Cooperativas No Agropecuarias»...

67 Cfr. Art. 13 c) Decreto Ley No. 366... 
presentadas en el momento de su conformación como cooperativas y deudas vencidas ${ }^{68}$.

\section{Conclusiones}

1. La cooperativa no agropecuaria en Cuba es una organización con fines económicos y sociales, que se constituye voluntariamente sobre la base del aporte de bienes y derechos y se sustenta en el trabajo de sus socios. Asumen la configuración de una cooperativa de trabajo asociado. Las mismas se sustentan en los principios siguientes: la voluntariedad, cooperación y ayuda mutuas, decisión colectiva e igualdad de derechos de los socios, autonomía y sustentabilidad económicas, disciplina cooperativista, responsabilidad social, contribución al desarrollo planificado de la economía y al bienestar de los socios y sus familiares, colaboración y cooperación entre cooperativas y otras entidades, y educación y formación.

2. Las huellas socioeconómicas de la creación y funcionamiento de las CNoA en Cuba no son homogéneas. Esto producto a la diversidad de actividades productivas y servicios que comprende el sector; los diferentes órganos de relación que las atienden y la relaciones de las cooperativas con estos órganos; la manera en que fueron creadas - creación espontánea o inducidas-, lo que determina el nivel de compromiso con sus asociados y familias y luego con la comunidad; así como su rentabilidad económica acompañada de la presencia o no de la idea de la cooperativa como proyecto colectivo y el cumplimiento de la responsabilidad social.

3. Los vestigios que han dejado las CNoA en el ámbito socioeconómico, luego de siete años de creadas se concentran en ${ }^{69}$ : a) Fuente de empleo y mejora salarial; b) Perfeccionamiento de la actividad que realiza y de la organización del trabajo —equidad en la obtención del beneficio-; c) Contribución al bienestar social de los socios y sus familias; d) Apoyo a las comunidades y centros de salud y educación.

4. Desde el punto de vista jurídico en Cuba las cooperativas han supuesto no pocos retos que se refieren a lo estrictamente legal-coopera-

68 MINISTERIO DE ECONOMÍA Y PLANIFICACIÓN.: «Perfeccionamiento del proceso experimental de la creación de cooperativas en sectores no agropecuarios». Seminario Nacional, La Habana, 2019, pp. 11-12.

69 Notas y valoraciones del I Taller sobre Cooperativismo agropecuario y no agropecuario. Jornada de celebración del V Aniversario de la CNoA de Contadores «Dr. Enrique Arnaldo Rodríguez Corominas». Villa Clara, 18 de octubre de 2019. 
tivo, pero también a la interpretación de otras disposiciones legales y su aplicabilidad. Estos se manifiestan en la necesidad de actualizar y armonizar el entorno jurídico cooperativo nacional, la educación de los socios, los aspirantes y los entes de relación en la identidad cooperativa, los principios y sus particularidades. Es de especial interés la necesidad de respeto al principio de autonomía cooperativa que afecta la gestión y funcionamiento de las mismas. También es necesario la instrumentación de un ente cooperativo nacional que agrupe a todas las cooperativas y armonice el movimiento cooperativo nacional.

5. La nueva legislación cooperativa aprobada en Cuba para las cooperativas no agrarias actualiza su marco jurídico, busca superar las problemáticas demostradas, pero aún subsisten en las mismas cuestiones que afectan el funcionamiento de estas organizaciones; tal es el caso de la indefinición en cuanto a su naturaleza jurídica, la complejidad en el procedimiento de constitución y aprobación, confusión en las funciones de los entes cooperativos, así como omisiones en torno al régimen patrimonial.

\section{Bibliografía}

AA.VV.: «Las Cooperativas valencianas. Manual de Constitución y Funcionamiento». Confederación de Cooperativas de la Comunidad Valenciana, 2013, p. 64.

Alfonso Alemán, J.: «Responsabilidad, gestión y balance social en las empresas cooperativas», Cooperativismo y Desarrollo, vol. 1, núm. 2, 2013, pp. 186198. Disponible en http://coodes.upr.edu.cu/index.php/coodes/article/view/ $61 / 173$

Alianza Cooperativa Internacional para las Américas: «Definición de Cooperativa», 1995. Disponible en Word Wide Web: http://www.aciamericas.coop/ Definicion-de-Cooperativa

Altuna Gabilond, L.; Loyola IDIakez, A.; Pagalday Tricio, E.: «Mondragón: los dilemas de un cooperativismo maduro», En: Piñelro HaRneCKer, C.: «Cooperativas y socialismo: una mirada desde Cuba». Editorial Caminos, La Habana, 2011 p. 215.

Campos Pérez, Y.: «El capital social cooperativo como manifestación del principio de participación económica. Análisis teórico-legal en Cuba». Boletín de la Asociación Internacional de Derecho Cooperativo, Núm.53, Bilbao, 2018. p. 173-205.

Carranza, J.; Monreal, P.; GutiérRez, L.: «Cuba: restructuración económica, socialismo y mercado». Revista Temas, No.1, pp. 27 y ss.

Donéstevez Sánchez, G.M., García Ruiz, J., Fajardo Nápoles, L., Figueras Matos, D., Muñoz Alfonso, Y., y Martinera Hernández, J. F.: «El nuevo cooperativismo en la Cuba del siglo XXI», En: Muñoz González, R., DonÉSTeVez SÁN- 
Chez, G.M., García Ruiz, J. (comp.), Desarrollo y cooperativismo. Desafíos al modelo cubano de transición al socialismo (pp. 141-162), Editorial Caminos, La Habana, 2014, p. 208.

García Müller, A.: «Derecho Cooperativo, Mutual y de la Economía Social y Solidaria». Mérida. Capítulo 6, 2019, p. 1.

HenRíquez, P.: «La participación en la gestión administrativa de la CNA Confecciones Model: un estudio de caso» (tesis de maestría), Departamento de Sociología, Universidad de La Habana, Cuba, 2017, p. 112.

Hernández Aguilar, O. y Rodríguez Musa, O.: «La cooperativa en el ordenamiento jurídico cubano. Una aproximación crítica a la luz del actual proceso de perfeccionamiento del modelo económico en el país». Boletín de la Asociación Internacional de Derecho Cooperativo, Núm. 45/2011, Bilbao, 2011, pp. 251-269.

Jiménez Guetón, R., y PADrón SÁnchez, N.: «Retos de las cooperativas no agropecuarias en el contexto actual cubano», En: García Ruiz, J., Figueras Matos, D., y González Mastrapa, E. (comp.). Sector cooperativo y desarrollo local (pp. 84-89), Editorial Feijóo, La Habana, 2016, p.155.

MinisTeRIO de ECONOMÍA Y PLANIFICACIÓN: Perfeccionamiento del proceso experimental de la creación de cooperativas en sectores no agropecuarios. Seminario Nacional, La Habana, 2019, p. 5.

Montenegro Morales, M.: «Experiencias de buenas prácticas en la Cooperativa No Agropecuaria de Servicios de Construcción, Andamios y Cofres», Cooperativismo y Desarrollo (COODES), vol. 6, núm. 1, enero/junio 2018, pp. 108-119. Disponible en: http://coodes.upr.edu.cu/index.php/coodes/ article/view/192

Muñoz Alfonso, Y; López GonzÁlez, l.; Campos Pérez, Y.: «Las cooperativas no agropecuarias de primer grado en Cuba. Consideraciones críticas de su régimen jurídico». En Revista Jurídica de Economía Social y Cooperativa, n. ${ }^{\circ}$ 32. CIRIEC, Valencia, 2018. p. 142.

Nuñez LleRENA, C.: «La participación en la gestión de la Cooperativa No Agropecuaria Clavos para Herrar «Los Jiménez» del municipio Placetas» (tesis de diploma), Departamento de Sociología, Universidad Central «Marta Abreu» de Las Villas, Villa Clara, 2019, p. 100.

OJeDA SURIS, D.: «Las cooperativas no agropecuarias: dos años después», En: García Ruiz, J., Figueras Matos, D., y González Mastrapa, E. (comp.). Sector cooperativo y desarrollo local (pp. 76-83), Editorial Feijóo, La Habana, 2016, p. 155.

Partido Comunista de Cuba (PCC): Lineamientos de la Política Económica y Social del Partido y la Revolución para el período 2016-2021, No. 161.

PINO SANTOS, P.C.H.: "Una mirada internacional y nacional a las investigaciones sobre participación en la gestión cooperativa», Alternativas cubanas en Psicología, vol. 6, núm. 16, enero/abril 2018, pp. 23-35. Disponible en https:// www.acupsi.org/articulo/209/una-mirada-internacional-y-nacional-a-lasinvestigaciones-sobre-participacin-en-la-gestin-cooperativa.html

PINEEIRO HARneCKeR, C.: «Cooperativas y socialismo: una mirada desde Cuba». Editorial Caminos, La Habana, 2011 p. 34. 
PiñeIRO HaRneCKer, C.: «Nuevas cooperativas cubanas: logros y dificultades», 2015. Disponible en: https://www.researchgate.net/publication/284177761_ Nuevas_cooperativas_cubanas_logros_y_dificultades_marzo_2015

Piñeiro, C.; Pérez, D.; Reinoso, O.; Padrón, N., y Hernández, M.: «Reporte de investigación de cooperativas no agropecuarias. Informe del Centro de Estudios de la Economía Cubana», Universidad de La Habana, Cuba, 2014, p. 42.

Reyes LavegA, S.: «Aportes para una ley de cooperativas». Fundación Friedrich Ebert, República Dominicana, 2012. p 1.

Reyes LAVEGA, S.: «Las especiales características de las cooperativas». Fundación Friedrich Ebert, República Dominicana, 2012. p. 1.

Rivera Rodríguez, C.A.; Labrador Machín, O.; y Alfonso Alemán, J.L.: «Retos del cooperativismo como alternativa de desarrollo ante la crisis global. Su papel en el modelo económico cubano», En: PIÑEIRO HARNECKER, C. (comp.), Cooperativas y socialismo. Una mirada desde Cuba (pp. 397-415), Editorial Caminos, La Habana, 2011, p. 420.

Rodríguez MusA, O.: «Presupuestos teóricos para el redimensionamiento constitucional de la cooperativa en Cuba». Tesis presentada en opción al grado científico de Doctor en Ciencias Jurídicas. La Habana, 2016. p. 26.

SANz LARA, A.: "Las cooperativas no agropecuarias en Cuba en el contexto de transformación de la Cuba de hoy. Desafíos actuales», XII Congreso Nacional de Estudios del Trabajo, Buenos Aires, 2015. Disponible en: https:// www.aset.org.ar/2015/ponencias/11_Sanz.pdf

Soto Aleman, L.; González Ferrer, Y.; Llanes Guerra, O.: «El Balance Social Cooperativo en Cuba: Estado de la cuestión», En: SCHUJMAN, M.S., ITURRASPE Oviedo, F., Fajardo García, I.G., Chaves Gaudio, R.: La participación de los asociados en las entidades de la economía social y solidaria. Cooperativas de trabajo asociado. Autogestión. Carta del trabajador autogestionario. Investigación: La participación de los Asociados en las entidades de la Economía Social y Solidaria, Editorial de la Universidad Nacional de Rosario, Argentina, 2019, pp. 46-69.

SUÁREZ, Y.: «La responsabilidad social de las cooperativas urbanas y su contribución al desarrollo local en el municipio Centro Habana» (tesis de diploma), Departamento de Sociología, Universidad de La Habana, Cuba, 2014, p. 88.

TERRY, Y.: «Relaciones socioeconómicas en los mercados cooperativos del municipio Plaza de la Revolución» (tesis de diploma), Departamento de Sociología, Universidad de La Habana, Cuba, 2016, p. 94.

Vega Mato, J.: Entrevista ofrecida al periódico Granma en fecha 29 de agosto de 2019 periodista Castro Morales, Y. «Nuevas normas jurídicas que actualizan y perfeccionan la legislación sobre las cooperativas no agropecuarias».

VuotTo, M.: «Las cooperativas no agropecuarias y la transformación económica: políticas, procesos y estrategias», REVESCO, núm. 120, enero/ abril 2016, pp. 149-181. Disponible en https://www.researchgate.net/ publication/282467022_Las_cooperativas_no_agropecuarias_y_la_ transformacion_economica_en_Cuba_politicas_procesos_y_estrategias. 


\section{Legislación consultada}

Constitución de la República de Cuba, 2019. Art. 22 b). Gaceta Oficial n. ${ }^{\circ} 5$ Extraordinaria de 10 de abril de 2019.

Constitución de la RepúbliCA de CUBA, 1976. Gaceta Oficial Extraordinaria n. 7 del 1 de agosto de 1992.

DECRETO LEY 366. «De las cooperativas no agropecuarias no agropecuarias» de fecha 19 de noviembre de 2018 y publicado en la Gaceta Oficial de la República de Cuba a 30 de agosto de 2019.

DeCReto Ley No. 305, de 15 de noviembre de 2012, «De las Cooperativas No Agropecuarias». Gaceta Oficial 053 Extraordinaria de 11 de diciembre de 2012.

DeCRETo 356. «Reglamento de las Cooperativas No Agropecuarias». Gaceta Oficial n. ${ }^{\circ} 63$ Ordinaria de 30 de agosto de 2019. 


\section{Derechos de autor}

http://dec.revistas.deusto.es/

La revista Deusto Estudios Cooperativos es una revista de acceso abierto lo que significa que es de libre acceso en su integridad inmediatamente después de la publicación de cada número. Se permite su lectura, la búsqueda, descarga, distribución y reutilización legal en cualquier tipo de soporte sólo para fines no comerciales y según lo previsto por la ley; sin la previa autorización de la Editorial (Universidad de Deusto) o el autor, siempre que la obra original sea debidamente citada (número, año, páginas y DOI si procede) y cualquier cambio en el original esté claramente indicado.

\section{Copyright}

The Deusto Journal of Cooperative Studies is an Open Access journal which means that it is free for full and immediate access, reading, search, download, distribution, and lawful reuse in any medium only for non-commercial purposes, without prior permission from the Publisher or the author; provided the original work is properly cited and any changes to the original are clearly indicated. 